\title{
ON THE STABILITY OF THE FUNCTIONAL EQUATION
}

$$
f(x+y-x y)+x f(y)+y f(x)=f(x)+f(y)
$$

YONG-SOO JUNG

Abstract. In this paper we present a generalized version of the Hyers-Ulam stability and the superstability of the functional equation $f(x+y-x y)+x f(y)+y f(x)=f(x)+f(y)$, respectively.

Mathematics subject classification (2000): 39B72, 38B82, 47H15.

Key words and phrases: Functional equation, stability.

\section{REFERENCES}

[1] P. GǍVRUTA, A generalization of the Hyers-Ulam-Rassias stability of approximately additive mappings, J. Math. Anal. Appl 184 (1994), 431-436.

[2] D. H. Hyers, On the stability of the linear functional equation, Proc. Nat. Acad. Sci. 27 (1941), 222-224.

[3] D. H. Hyers, G. ISAC AND TH. M. RASSIAS, Stability of functional equations in several variables, Birkhäuser, 1998.

[4] D. H. HYERS, G. ISAC AND TH. M. RASSIAS, On the asymptoticity aspect of Hyers-Ulam stability of mappings, Aequationes Math. 126 (1998), 425-430.

[5] S. -M. Jung, On the superstability of the functional equation $f\left(x^{y}\right)=y f(x)$, Abh. Math. Sem. Univ. Hamburg 67 (1997), 315-322.

[6] K. -W. JUN AND Y. -H. LEE, On the Hyers-Ulam-Rassias stability of a pexiderized quadratic inequality, Math. Inequal. Appl. 4 (2001), 93-118.

[7] Gy. MaKsa, Problems 18, In 'Report on the 34th ISFE', Aequationes Math. 53 (1997), 194.

[8] Gy. MAKSA AND Zs. PÁles, Hyperstability of a class of linear functional equations, Acta Math. Acad. Paed. Nyhazi. 17 (2001), 107-112.

[9] Zs. PÁLES, Generalized stability of the Cauchy functional equation, Aequationes Math. 56 (1998), 222-232.

[10] Zs. PÁLES, Remark 27, In 'Report on the 34th ISFE', Aequationes Math. 53 (1997), 200-201.

[11] Zs. PÁles, P. VOLKMANN AND D. LuCE, Stability of functional equations with square-symmetric operations, Proc. Natl. Acad. Sci. 95, Issue 22 (1998), 12772-12775.

[12] TH. M. RASSIAS, On the stability of the linear mapping in Banach spaces, Proc. Amer. Math. Soc. 72 (1978), 297-300.

[13] TH. M. RASSIAS, On the stability of functional equations and a problem of Ulam, Acta Appl. Math. 62 (2000), 23-130.

[14] TH. M. RASSIAS, Functional equations and inequalities, Kluwer Academic Publishers, Dordrecht, 2000.

[15] F. SKof, Proprietá locali e approssimazione di opertori, Rend. Sem. Mat. Fis. Milano 53 (1983), 113-129.

[16] J. TABOR, Remarks 20, In 'Report on the 34th ISFE', Aequationes Math. 53 (1997), 194-196.

[17] J. TABOR, Stability of the Cauchy functional equation with variable bound, Publ. Math. Debrecen 51 (1997), 165-173.

[18] S. M. Ulam, Problems in Modern Mathematics., Chap. VI, Wiley, New York, 1964. 